\title{
Ar-37 emanation factors determined by irradiation experiments on soil samples
}

\author{
R. Purtschert ${ }^{1}$, S. Musy ${ }^{1}$, G. Dellepiane ${ }^{2}$, \\ S. BRACCINI ${ }^{2}$
}

${ }^{1}$ Climate and Environmental Physics, University of Bern, 3012 Bern, Switzerland (roland.purtschert@climate.unibe.ch,

stephanie.musy@climate.unibe.ch)

${ }^{2}$ Albert Einstein Center for Fundamental Physics

Laboratory for High Energy Physics, University of Bern,

(gaia.dellepiane@,lhep.unibe.ch, saverio.braccini@1hep.unibe.ch)

Underground production of radionuclides can be a blessing or curse for groundwater dating. Accumulation e.g. of ${ }^{222} \mathrm{Rn}$ or ${ }^{37} \mathrm{Ar}$ are tools to assess infiltration from surface waters to aquifers (1). Decay dating by cosmogenic isotopes such ${ }^{39} \mathrm{Ar}$ on the other hand may be affected by underground production and lead to underestimation of residence times. ${ }^{37} \mathrm{Ar}$ is relevant in both applications because its half-live of 35 days is long enough to extend the dating range of ${ }^{222} \mathrm{Rn}\left(\mathrm{T}_{1 / 2}: 3.8\right.$ d) and short enough to act as a neutron flux monitor for ${ }^{39} \mathrm{Ar}$ dating ( $\mathrm{T}_{1 / 2}: 269 \mathrm{yrs}$ ). The release rate from the mineral phase where ${ }^{37} \mathrm{Ar}$ is produced to the water filled pore space has to be known in both cases. Soil and rock samples were irradiated by thermal neutrons at the SWAN cyclotron in Bern (2). A gas extraction method has been developed in order to transfer ${ }^{37} \mathrm{Ar}$ that has been produced in the irradiation vessel by the ${ }^{40} \mathrm{Ca}(\mathrm{n}, \alpha)^{37} \mathrm{Ar}$ reaction to the proportional counter where the activity is measured. The elemental composition of the soil was previously determined by Fusion ICP/MS. The comparison between calculated production rates and released Ar-37 atoms revealed emanation factors in the range $2-10 \%$ depending on grain size and mineralogy of the samples.

1. O. S. Schilling et al., Advancing Physically-Based Flow Simulations of Alluvial Systems Through Atmospheric Noble Gases and the Novel 37Ar Tracer Method. Water Resources Research 53, 10465-10490 (2017).

2. M. Auger et al., in Nukleonika. (2016), vol. 61, pp. 11. 